\title{
Effect of Heterocyclic Pyrimidine Compounds on UVB-Induced Cell Damage in Human Keratinocytes and on Melanogenesis in Mouse B16 Cells
}

\author{
Nao Shimoda, ${ }^{a}$ Yasuko Mutou, ${ }^{a}$ Noriko Shimura, ${ }^{b}$ Mitsutoshi Tsukimoto, ${ }^{a}$ Akira Awaya, ${ }^{c}$ and \\ Shuji KолімА ${ }^{*} a$ \\ ${ }^{a}$ Faculty of Pharmaceutical Sciences, Tokyo University of Science (TUS); 2641 Yamazaki, Noda, Chiba 278-8510, Japan: \\ ${ }^{b}$ Faculty of Pharmaceutical Sciences, Ohu University; 31-1 Misumidou, Tomita-machi, Koriyama, Fukushima 963-8611, \\ Japan: and ${ }^{c}$ Dermatology and Epidemiology Research Institute; 4978 Totsuka-cho, Totsuka-ku, Yokohama, Kanagawa \\ 244-0003, Japan. \\ Received November 24, 2009; accepted February 2, 2010; published online February 5, 2010
}

We investigated the protective effect of several heterocyclic pyrimidine compounds against ultraviolet $B$ (UVB)-induced damage in human keratinocyte $\mathrm{HaCaT}$ cells, as well as the inhibitory effect on melanogenesis in B16 melanoma cells. One of the compounds examined, 2-piperadino-6-methyl-5-oxo-5,6-dihydro(7H)pyrrolo[3,4$d$ ]pyrimidine maleate (MS-818), showed low cytotoxicity even at $500 \mu \mathrm{M}$. At $50-500 \mu \mathrm{M}$, MS-818 dose-dependently suppressed the UVB $\left(100 \mathrm{~mJ} / \mathrm{cm}^{2}\right)$-induced elevation of tumor necrosis factor alpha (TNF- $\left.\alpha\right)$, one of the

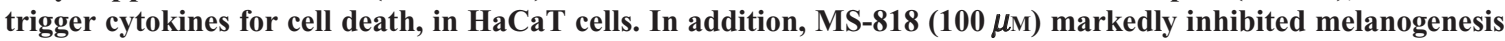
in B16 melanoma cells via downregulation of tyrosinase expression mediated by microphthalmia-associated transcription factor (MITF) and extracellular signal-regulated kinase (ERK). In conclusion, MS-818 protected epidermal cells from UVB-induced damage and also suppressed melanogenesis in melanoma cells. It appears to be a good candidate for a new UVB-protective and whitening agent for application in cosmetics.

Key words heterocyclic pyrimidine compound; inhibition; UVB-damage; melanogenesis; tyrosinase; MS-818

Solar ultraviolet radiation is divided into three categories, UVC (>290 nm), UVB ( $290-320 \mathrm{~nm})$, and UVA (320$400 \mathrm{~nm})$. Short-wavelength UV, i.e., UVC and a part of UVB, is mostly absorbed by the ozone layer, and does not reach the earth's surface. ${ }^{1)}$ Although UVB that does reach the surface represents only $4 \%$ of the total environmental UV radiation, ${ }^{2)}$ it has a stronger phototoxic effect than UVA, because DNA shows an absorption maximum at about $260 \mathrm{~nm}$ with an absorption tail in the UVB region. ${ }^{3)}$ Thus, solar UVB has many adverse effects on human skin, including cancer, immunosuppression, erythema, hyperpigmentation, and photoaging. ${ }^{410)}$

UVB radiation that penetrates the epidermis stimulates keratinocytes to produce inflammatory cytokines, such as interleukin (IL)-1, IL-10, and tumor necrosis factor (TNF)$\alpha .{ }^{11-13)}$ This UVB-induced IL-10 and TNF- $\alpha$ production leads to immunosuppression, ${ }^{14,15)}$ and TNF- $\alpha$ also contributes to apoptotic death of keratinocytes. ${ }^{16)}$ In addition, UVB radiation induces DNA damage, such as formation of cyclobutane pyrimidine dimers (CPDs) and 6-4 photoproducts, ${ }^{17)}$ and if the damage is irreparable, cells undergo apoptosis. ${ }^{18)}$

Another UV-induced biological effect is melanogenesis in melanocytes. ${ }^{19}$ ) Melanin biosynthesis is catalyzed by three melanocyte-specific enzymes: tyrosinase, TRP-1 and TRP-2. ${ }^{20)}$ The expression of these enzymes is strongly regulated by microphthalmia-associated transcription factor (MITF). ${ }^{21,22)}$ The extracellular signal-regulated kinase (ERK) signaling cascade, which plays a crucial role in cell proliferation and differentiation, also participates in down-regulation of MITF. ${ }^{23-25)}$ Among the above three enzymes, tyrosinase is the rate-limiting enzyme in melanin biosynthesis and catalyzes the hydroxylation of tyrosine to 3,4-dihydroxyphenylalanine (DOPA) and oxidation of DOPA to dopaquinone. ${ }^{26)}$
Though melanin plays a crucial role in the prevention of UVinduced skin damage, ${ }^{27)}$ overproduction and accumulation of melanin are associated with hyperpigmentation problems, such as formation of freckles, melasma, and ephelides. ${ }^{28)}$ As life expectancy increases, lifetime UV exposure will also increase, and so there is increasing interest in agents that can protect the skin from UV radiation or control pigmentation.

Various heterocyclic pyrimidine compounds have been synthesized for screening of at first antibacterial and herbicidal activity. ${ }^{29)}$ However, from novel strategic studies, these compounds have been elucidated to have a variety of biological activities, including promotion of neurite outgrowth, ${ }^{29)}$ neuronal differentiation, ${ }^{30)}$ and astrocyte differentiation, ${ }^{31)}$ suppression of neuronal apoptosis, ${ }^{32)}$ regeneration of injured peripheral nerves, ${ }^{33)}$ fracture repair, ${ }^{34)}$ angiogenesis, ${ }^{35,36)}$ and superovulation, ${ }^{37)}$ etc. On the other hand, the effects of the compounds on skin damage induced by UVB radiation have not been investigated. In the present study, we examined the effects of five heterocyclic pyrimidine compounds on UVBinduced damage to human keratinocytes ( $\mathrm{HaCaT}$ cells) and on melanogenesis in mouse B16 melanoma cells.

\section{MATERIALS AND METHODS}

Reagents The following antibodies were used for TNF- $\alpha$ assay: purified anti-mouse TNF- $\alpha$ mAb (1F3F3D4), biotinconjugated anti-mouse TNF- $\alpha$ mAb (MP6-XT22), and recombinant mouse TNF- $\alpha$ were purchased from eBioscience (San Diego, CA, U.S.A.).

For assay of tyrosinase activity in cell-free system, mushroom tyrosinase and L-DOPA were obtained from Wako Pure Chemicals Co., Ltd. (Osaka, Japan).

For Western blotting, the primary antibodies used were anti-MITF antibody (ab13703) (Abcam, Cambridge, U.K.), 
anti-tyrosinase antibody (ab52493) (Abcam, Cambridge, U.K.), anti-rat ERK1/2 antibody (Cell Signaling Technology, Inc., Beverly, MA, U.S.A.), and anti-phosphorylated-ERK1/2 antibody (Cell Signaling Technology, Inc., Beverly, MA, U.S.A.). The secondary antibodies used were anti-rabbit immunoglobulin $\mathrm{G}$ (IgG) horse raddish peroxidase (HRP)linked antibody (\#7074) (Cell Signaling Technology, Inc., Beverly, MA, U.S.A.) and anti-mouse IgG-HRP (sc-2005) (Santa Cruz Biotechnology, Santa Cruz, CA, U.S.A.). To normalize the amount of total protein, anti- $\beta$-actin antibody (Santa Cruz Biotechnology, Santa Cruz, CA, U.S.A.) was used in this analysis.

Heterocyclic Pyrimidine Compounds Heterocyclic pyrimidine compounds, 2-piperadino-6-methyl-5-oxo-5,6-dihydro $(7 H)$ pyrrolo[3,4- $d$ ]pyrimidine maleate (MS-818, eiwanei, A1A), was synthesized as previously described (PMID: 8364468). ${ }^{29)}$ Other compounds, 2-piperadino-7-methyl-6oxo-5,6-dihydro(7H)pyrrolo[2,3-d]pyrimidine maleate $(\mathrm{MS}-820),{ }^{29)}$ 2-piperidino-7-methyl-6-oxo-5,6-dihydro $(7 H)$ pyrrolo[2,3- $d]$ pyrimidine maleate (MS-430), ${ }^{31)}$ 2-piperidino4-(2-oxo-pyrrolidino)pyrimidine hydrochloride (MS-210), ${ }^{31)}$ and 2-p-ethylpiperidino-7-methyl-6-oxo-5,6-dihydro(7H)pyrrolo[2,3- $d]$ pyrimidine maleate (MS-861), ${ }^{29)}$ were gifts from Mitsui Pharmaceuticals, Inc., Japan. The chemical structures of these compounds are shown in Fig. 1.

Cell Culture Human epidermal keratinocyte $\mathrm{HaCaT}$ cells (kindly provided by Dr. K. Takeda) and mouse B16 melanoma cells were cultured in Dulbecco's modified Eagle's medium (DMEM, Wako Pure Chemicals Co., Ltd., Osaka, Japan) containing $10 \%$ heat-inactivated FBS, 100 units $/ \mathrm{ml}$ penicillin $\mathrm{G}$ and $100 \mathrm{mg} / \mathrm{ml}$ streptomycin with $5 \% \mathrm{CO}_{2}$ at $37^{\circ} \mathrm{C}$. For experiments, $\mathrm{HaCaT}$ cells were seeded on a<smiles>CN1Cc2nc(N3CCNCC3)ncc2C1=O</smiles><smiles>CN1C(=O)Cc2cnc(N3CCNCC3)nc21</smiles>

MS-818

MS-820

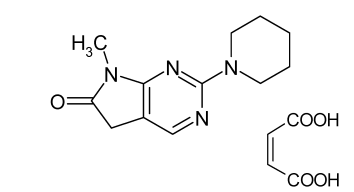

MS-430

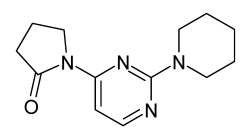

$\mathrm{HCl}$

MS-210

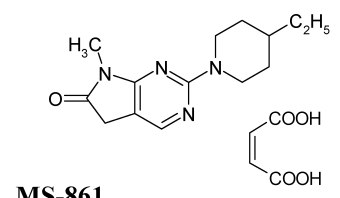

MS-861

Fig. 1. Chemical Structures of Heterocyclic Pyrimidine Compounds Used in This Work

MS-818; 2-piperadino-6-methyl-5-oxo-5,6-dihydro(7H)pyrrolo[3,4- $d$ ] pyrimidine maleate, MS-820; 2-piperadino-7-methyl-6-oxo-5,6-dihydro(7H)pyrrolo[2,3-d]pyrimidine maleate, MS-430; 2-piperidino-7-methyl-6-oxo-5,6-dihydro $(7 H)$ pyrrolo[2,3- $d]$ pyrimidine maleate, MS-210; 2-piperidino-4-(2-oxo-pyrrolidino)pyrimidine hydrochloride, MS-861; 2-p-ethylpiperidino-7-methyl-6-oxo-5,6-dihydro(7H)pyrrolo[2,3- $d]$ pyrimidine maleate.
$35 \mathrm{~mm}$ dish and mouse B16 melanoma cells were seeded on a 48-well plate, a 6-well plate, or a $60 \mathrm{~mm}$ dish.

Cell Viability of HaCaT Cells Cytotoxicity of MS compounds to $\mathrm{HaCaT}$ cells were determined by means of lactate dehydrogenase (LDH) assay. MS-818 and MS-820 were dissolved in phosphate buffered saline (PBS) and then adjusted to an appropriate concentration with culture medium. Other MS compounds were first dissolved in only a little ethyl alcohol and then adjusted to an appropriate concentration with culture medium. After incubation, culture supernatant was collected and centrifuged at $3000 \mathrm{rpm}$ for $3 \mathrm{~min}$. The supernatant were subjected to the assay. LDH activity was determined colorimetrically with a Cytotoxicity Detection Kit (Roche Applied Science, Indianapolis, IN, U.S.A.). Cytotoxicity and viability were calculated in accordance with the manufacturer's instructions.

UVB Irradiation and Treatment with MS Compounds A UVB lamp (HP-30LM; Atto Co., Japan) with 280$320 \mathrm{~nm}$ emission peaking at $312 \mathrm{~nm}$ was used. The UVB fluence rate was simultaneously measured and integrated using a radiometer (UVX-31; UVP, Inc., U.S.A.) with a $310 \mathrm{~nm}$ detector placed at the same distance from the UVB source as the cells.

$\mathrm{HaCaT}$ cells were grown in a $35 \mathrm{~mm}$ dish to confluence and treated with different concentrations of MS compounds in DMEM culture medium $1 \mathrm{~h}$ before or immediately after UVB irradiation. The cells were exposed to UVB (10$\left.100 \mathrm{~mJ} / \mathrm{cm}^{2}\right)$ through the DMEM culture medium $(1 \mathrm{ml} /$ $35 \mathrm{~mm}$ dish). UVB-irradiated cells were incubated with DMEM culture medium in $5 \% \mathrm{CO}_{2}$ at $37^{\circ} \mathrm{C}$ for $12 \mathrm{~h}$ and $24 \mathrm{~h}$.

Cell Viability of B16 Melanoma Cells The effect of MS-818 on the proliferation of B16 melanoma cells was determined by means of MTT assay. B16 melanoma cells were seeded in a 48 -well plate at a density of $5 \times 10^{3}$ per well and allowed to attach for $24 \mathrm{~h}$. Then the cells were incubated in fresh medium containing various concentrations of MS-818 for $72 \mathrm{~h}$. After incubation, MTT (3-(4,5-dimethylthiazol-2yl)-2,5-diphenyltetrazolium bromide) solution was added to each well at a final concentration of $0.05 \%$. After further incubation for $4 \mathrm{~h}$, stop solution $(10 \%$ sodium dodecyl sulfate (SDS) in $0.1 \% \mathrm{HCl}$ ) was added to each well and incubation was continued for another $18 \mathrm{~h}$. Then, the cell viability were estimated in terms of the absorbance at $590 \mathrm{~nm}$.

Chromatin Condensation To investigate the effects of MS-818 on UVB-induced apoptosis, changes in the nuclear morphology of cells undergoing apoptosis were detected by staining with the DNA-binding fluorochome Hoechst 33342. $\mathrm{HaCaT}$ cells were cultured on a glass coverslip, treated with MS-818 and UVB-irradiation and incubated for $12 \mathrm{~h}$. After the incubation, the cells were washed with PBS twice and fixed in methanol overnight at $-20^{\circ} \mathrm{C}$, then stained with $10 \mu \mathrm{g} / \mathrm{ml}$ Hoechst 33342 for $10 \mathrm{~min}$ at room temperature. Coverslips were observed with a fluorescence microscope, and the numbers of apoptotic nuclei in fields of 200 cells were counted.

Enzyme-Linked Immunosolvent Assay (ELISA) Procedures Production of TNF- $\alpha$ in HaCaT cells was measured by ELISA. At $24 \mathrm{~h}$ after UVB irradiation together with preor post-treatment with MS-818, culture supernatants of $\mathrm{HaCaT}$ cells were collected and stored at $-80^{\circ} \mathrm{C}$ until 
ELISA for measurement of TNF- $\alpha$ production.

Flat-bottomed 96-well Maxisorp plates were coated with purified TNF- $\alpha$ mAb overnight at $4{ }^{\circ} \mathrm{C}$. The primary mAb was removed, and the wells were washed 3 times with wash buffer $(0.05 \%$ Tween 20 in PBS), then blocked with blocking buffer ( $1 \%$ bovine serum albumin (BSA) in PBS) for $1 \mathrm{~h}$ at room temperature. The wells were washed 3 times, then $100 \mu \mathrm{l}$ aliquots of standard (recombinant mouse TNF- $\alpha$ ) and sample were added to each well, and the plates were incubated for $2 \mathrm{~h}$ at room temperature. The plate was washed 3 times with wash buffer, then biotin-labeled TNF- $\alpha$ mAb was added, and incubation was continued for $1 \mathrm{~h}$ at room temperature. The solutions in the wells were removed and the wells were washed 5 times with wash buffer. Next, $100 \mu \mathrm{l}$ of avidin-HRP was added to each well, and the plate was incubated for $30 \mathrm{~min}$ at room temperature. The color reaction was quenched with stop solution $\left(50 \mu \mathrm{l}, 2.5 \mathrm{M} \mathrm{H}_{2} \mathrm{SO}_{4}\right)$. The absorbance at $450 \mathrm{~nm}$ was measured with a spectrofluorophotometer (RF-1500: Shimadzu, Japan) and sample concentration was determined from the absorbance with reference to a standard curve. The determination range was 1.0 $62.5 \mathrm{pg} / \mathrm{ml}$, and samples were appropriately diluted to obtain a concentration within this range.

Melanin Content B16 melanoma cells were seeded in a 6 -well plate at a density of $2.5 \times 10^{4}$ cells per well and allowed to attach for $24 \mathrm{~h}$. Then the cells were incubated in fresh medium containing $100 \mu \mathrm{M}$ MS-818 for $72 \mathrm{~h}$. After incubation, the cells were washed with PBS and detached by means of a short incubation with ethylenediaminetetraacetic acid (EDTA). After centrifugation, the cell pellets were photographed and solubilized in $100 \mu \mathrm{l}$ of $1 \mathrm{M} \mathrm{NaOH}$ at $80^{\circ} \mathrm{C}$ for $1 \mathrm{~h}$. The melanin contents were estimated from the absorbance at $405 \mathrm{~nm}$, and values were corrected for the amount of proteins.

Assay of Tyrosinase Activity in Cell-Free System A cell-free system was used to investigate the direct effects of MS-818 on tyrosinase activity. Eighty microliters of $0.1 \mathrm{M} \mathrm{Na}$ phosphate buffer ( $\mathrm{pH}$ 7.0) containing MS-818 (final concentration: 10,50 and $100 \mu \mathrm{M}$ ) was mixed with $20 \mu \mathrm{l}$ of $200 \mathrm{U} / \mathrm{ml}$ mushroom tyrosinase, and incubated for $10 \mathrm{~min}$. After incubation, $50 \mu \mathrm{l}$ of $5 \mathrm{~mm}$ L-DOPA was added. Incubation was continued for $10 \mathrm{~min}$ at $37^{\circ} \mathrm{C}$, then the absorbance was measured at $490 \mathrm{~nm}$.

Western Blotting B16 melanoma cells were treated with $100 \mu \mathrm{M}$ MS-818 or MS-820 for $72 \mathrm{~h}$. After treatment, the cells were washed with cold PBS twice and lysed in cold lysis buffer (10 mM HEPES-NaOH pH 7.4, 1\% Triton X-100, $5 \mathrm{~mm}$ 2Na-EDTA, $30 \mathrm{~mm}$ sodium pyrophosphate, $50 \mathrm{~mm}$ sodium fluoride, $1 \mathrm{~mm}$ sodium $o$-vanadate) containing protease inhibitor cocktail. Proteins ( $30 \mu \mathrm{g}$ per lane) were separated by means of $10 \%$ SDS-PAGE and transferred to a nitrocellulose membrane. The membranes were blocked with $1 \%$ BSA in TBS-T buffer. MITF, tyrosinase, ERK and pERK were detected with anti-MITF antibody (dilution 1:1000, anti-tyrosinase antibody (dilution $1: 1000$ ), anti-rat ERK1/2 antibody, and anti-phosphorylated-ERK1/2 antibody, respectively. The nitrocellulose membrane was further incubated with anti-rabbit IgG HRP-conjugated antibody and antimouse IgG-HRP.

Bound antibodies were detected using ECL Western blotting detection reagents according to the manufacturer's in- structions. Equal loading was confirmed using anti- $\beta$-actin antibody to normalize the amount of total protein.

Statistical Analysis Data are presented as mean \pm S.E. The significance of differences was evaluated by means of ANOVA and $p$ values of less than 0.05 were considered statistically significant.

\section{RESULTS}

Cytotoxicity of MS Compounds to HaCaT Cells First, we investigated the effect of MS compounds on the viability of $\mathrm{HaCaT}$ cells by means of $\mathrm{LDH}$ assay. HaCaT cells were treated with different concentrations of each MS compound $(50-500 \mu \mathrm{M})$. As shown in Fig. 2, MS-818 and MS-820 showed low cytotoxicity even at $500 \mu \mathrm{M}$, whereas the other compounds exhibited high cytotoxicity. Therefore, we focused on MS-818 and MS-820 for further examination.

Dose-Dependent Effect of UVB on Viability of HaCaT Cells Changes in HaCaT cell viability after UVB irradiation $\left(10-100 \mathrm{~mJ} / \mathrm{cm}^{2}\right)$ were examined by means of $\mathrm{LDH}$
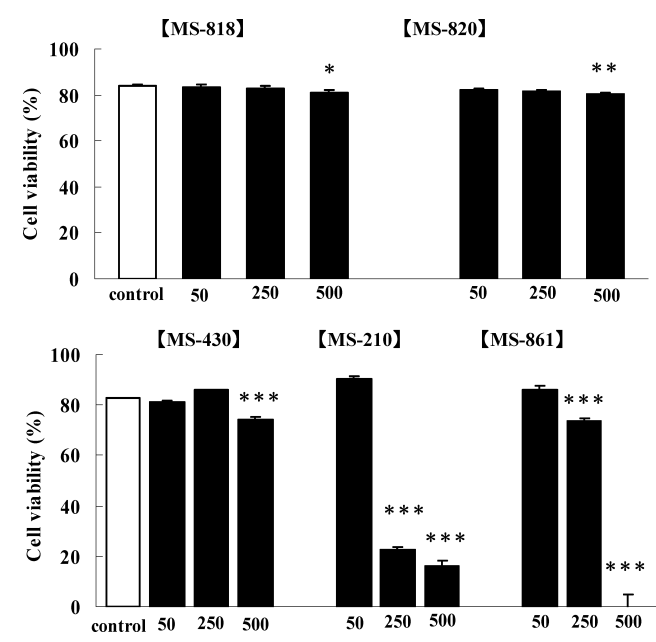

Fig. 2. Cytotoxicity of MS Compounds to HaCaT Cells

$\mathrm{HaCaT}$ cells were incubated with different concentrations of each compound for $24 \mathrm{~h}$ and a part of the medium was collected for LDH assay. The activity is expressed as a percentage of the total content determined by lysing an equal amount of cells with $1 \%$ Triton $\mathrm{X}-100$. The data represent the mean \pm S.E. of 3 independent experiments. $*(p<0.05), * *(p<0.01), * * *(p<0.005)$ indicates significant differences compared with the control.

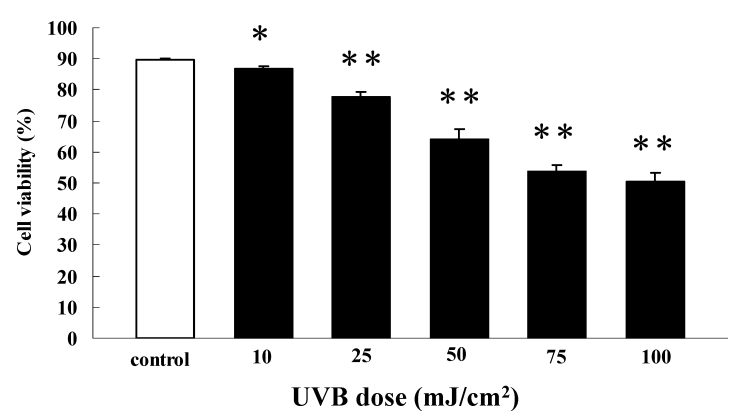

Fig. 3. Dose-Dependent Effect of UVB on Viability of HaCaT Cells $24 \mathrm{~h}$ after Irradiation

$\mathrm{HaCaT}$ cells were exposed to UVB at doses ranging from 10 to $100 \mathrm{~mJ} / \mathrm{cm}^{2}$, and the cell viability was examined at $24 \mathrm{~h}$ post-irradiation. LDH activity is expressed as a percentage of total content determined by lysing an equal amount of cells with $1 \%$ Triton $\mathrm{X}-100$. The data represent the mean \pm S.E. of 3 independent experiments. $*(p<0.01)$ and $* *(p<0.005)$ indicates significant differences compared with the control. 
assay. As shown in Fig. 3, the viability of HaCaT cell was dose-dependently reduced by UVB-irradiation, reaching $50 \%$ at the highest dose of $100 \mathrm{~mJ} / \mathrm{cm}^{2}$.

Effects of Pre- and Post-treatment with MS-818 or 820 on Viability of HaCaT Cells $24 \mathrm{~h}$ after UVB Irradiation $\mathrm{HaCaT}$ cells were treated with MS-818 or MS-820 before or after UVB-irradiation $\left(50 \mathrm{~mJ} / \mathrm{cm}^{2}\right)$ at concentrations of 50 , 250 , and $500 \mu \mathrm{M}$. At $24 \mathrm{~h}$ post-irradiation, the viability of the cells was evaluated. As shown in Fig. 4, pre-treatment with MS-818 significantly and dose-dependently blocked the UVB-induced decrease of cell viability. Post-treatment with MS-818 was ineffective, except at the highest dose of $500 \mu \mathrm{M}$.

In contrast, neither pre- nor post-treatment with MS-820

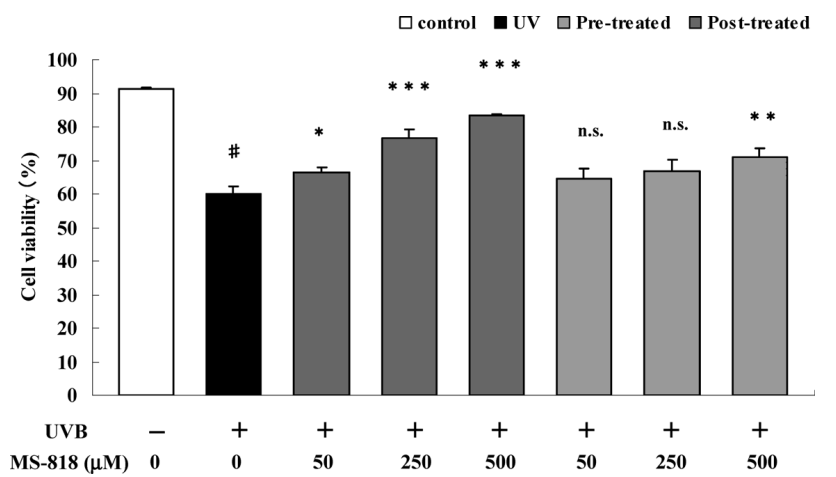

Fig. 4. Effects of Pre- and Post-treatment with MS-818 or -820 on Viability of HaCaT Cells $24 \mathrm{~h}$ after UVB Irradiation

$\mathrm{HaCaT}$ cells were irradiated with UVB at a dose of $50 \mathrm{~mJ} / \mathrm{cm}^{2}$. The cells were treated with MS-818 or MS-820 at concentrations of 50,250 and $500 \mu \mathrm{M}$ before or after irradiation. The data represent the mean \pm S.E. of 3 independent experiments. $\#(p<0.05)$ in dicates a significant difference compared with the non-irradiated control group and $*(p<0.05), * *(p<0.01), * * *(p<0.005)$ indicate significant differences compared with the UVB-irradiated group.
(A)

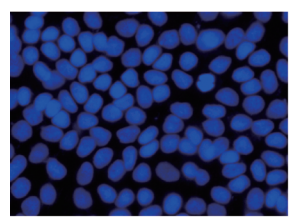

UV

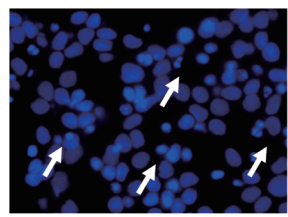

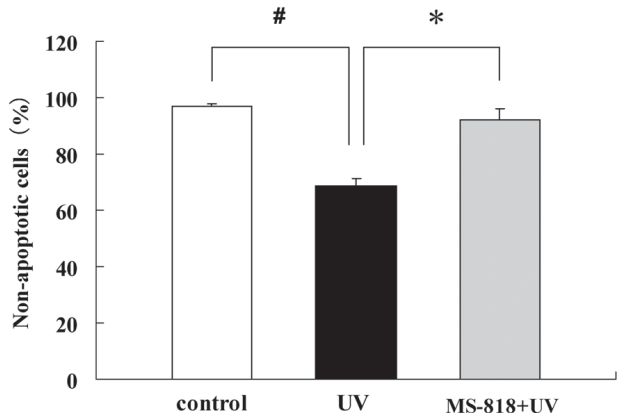

UV
MS-818 + UV

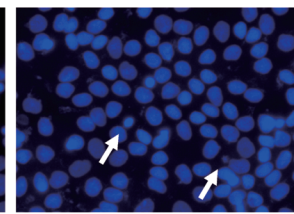

(B)

-818 on Morphological Changes in HaCaT Cells at Fig. 5. Effect of MS-818 on Morphological Chan
$12 \mathrm{~h}$ after UVB Irradiation at a Dose of $50 \mathrm{~mJ} / \mathrm{cm}^{2}$

Morphological changes of the cells were observed with a fluorescence microscope after staining with the DNA-binding fluorochome Hoechst 33342, and the numbers of apoptotic nuclei in fields of 200 cells were counted. (A) Morphological changes. White arrows show condensed chromatin. (B) Non-apoptotic cell ratio (\%). The numbers of apoptotic cells in fields of 200 cells were counted. The data represent the mean \pm S.E. of 3 independent experiments. $\#(p<0.05)$ indicates a significant difference compared with the non-irradiated control group, and $*(p<0.05)$ indicates a significant difference compared with the UVB-irradiated group.

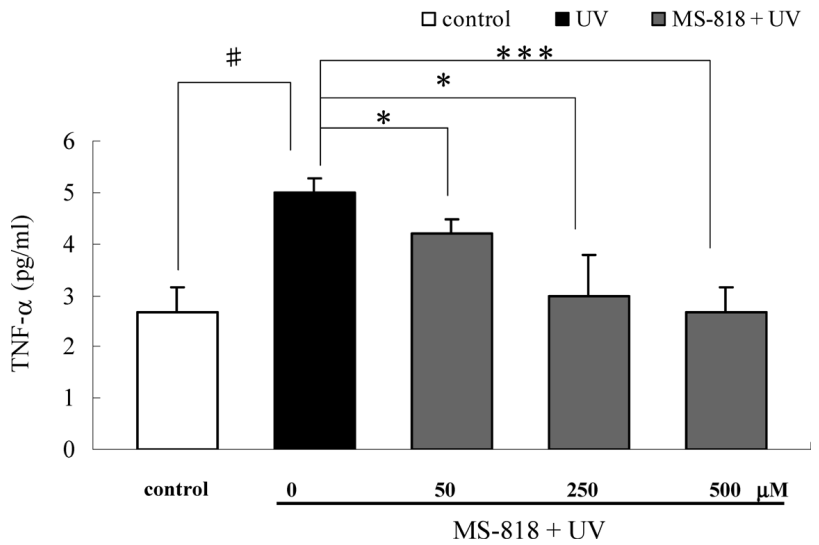

Fig. 6. Effect of MS-818 on TNF- $\alpha$ Production of HaCaT Cells $24 \mathrm{~h}$ after UVB Irradiation

$\mathrm{HaCaT}$ cells were irradiated by UVB at a dose of $100 \mathrm{~mJ} / \mathrm{cm}^{2}$. The cells were treated with MS-818 at the concentration of 50,250 or $500 \mu \mathrm{M}$ before or after irradiation. After $24 \mathrm{~h}$ incubation, a part of the medium was used for TNF- $\alpha$ assay. The data represent the mean \pm S.E. of 3 independent assays. $\#(p<0.05)$ indicates significant differences compared with the non-irradiated control group. $*(p<0.05)$, $* *(p<0.01)$, and $* * *(p<0.005)$ indicate significant differences compared with the UVB-irradiated group.

(A)

control MS-818

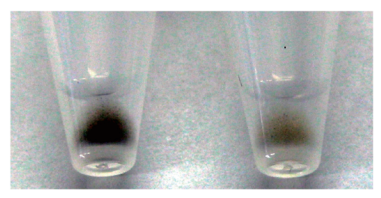

(B)

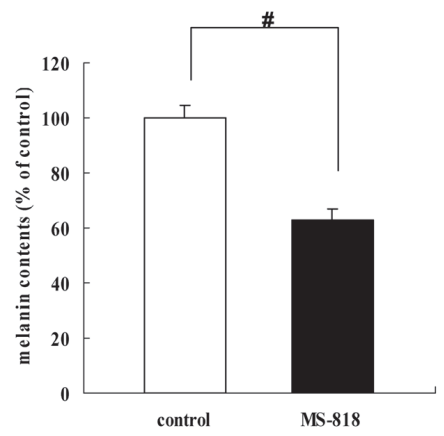

(C)

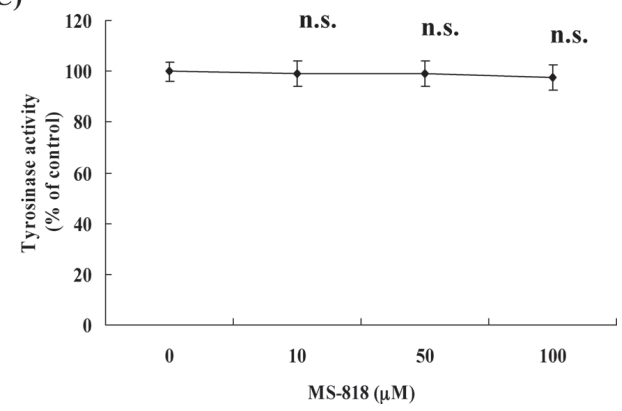

Fig. 7. Effect of MS-818 on Melanogenesis in B16 Melanoma Cells and on Tyrosinase Activity in a Cell-Free System

(A) Photograph of precipitated B16 melanoma cells. Cells were incubated for $72 \mathrm{~h}$ with and without $100 \mu \mathrm{M}$ MS-818. (B) Comparison of melanin contents between the control and MS-818-treated group. Melanin content was calculated from the absorbance at $405 \mathrm{~nm}$. Each value represents the mean \pm S.E. of 3 independent experiments. \# $(p<0.05)$ indicates a significant difference compared with control group. (C) Tyrosinase activity. Tyrosinase activity was measured using L-DOPA and mushroom tyrosinase. The amount of generated dopaquinone was determined by measuring the absorbance at $490 \mathrm{~nm}$. Tyrosinase activity is expressed as a percentage of the control value (taken as $100 \%$ ). Each value represents the mean \pm S.E. of 3 independent assays. 
had any significant effect (data not shown). Thus, we focused on MS-818 in subsequent experiments except for the experiment on "Effect of MS compounds on protein expression of MITF and tyrosinase."

Effect of MS-818 on Morphological Changes in HaCaT Cells Induced by UVB Irradiation To investigate the effect of MS-818 on UVB-induced apoptosis, we examined chromatin condensation, a typical apoptotic feature, by staining $\mathrm{HaCaT}$ cells with Hoechst 33342. As shown in Figs. 5A and $\mathrm{B}$, extensive chromatin condensation was seen at $12 \mathrm{~h}$ post-irradiation with UVB at $50 \mathrm{~mJ} / \mathrm{cm}^{2}$. This condensation was significantly blocked by pre-treatment with MS-818 $(500 \mu \mathrm{M})$. Thus, pre-treatment with MS-818 could protect $\mathrm{HaCaT}$ cells from UVB-induced cell damage.

Effect of MS-818 on UVB-Induced Elevation of TNF- $\alpha$ Production in HaCaT Cells It is well-known that UVB induces production of inflammatory cytokines, such as TNF- $\alpha$ and IL-10, in cells. Here, we examined the effect of MS-818 on the UVB-induced elevation of TNF- $\alpha$ production in $\mathrm{HaCaT}$ cells. As shown in Fig. 6, UVB-irradiation at $100 \mathrm{~mJ} / \mathrm{cm}^{2}$ significantly elevated TNF- $\alpha$ production in $\mathrm{HaCaT}$ cells. This elevation was dose-dependently inhibited by pre-treatment with MS-818. However, post-treatment with MS-818 was ineffective (data not shown). Thus, MS- 818 pretreatment suppressed the UVB-induced elevation of TNF- $\alpha$ production.

Effects of MS-818 on Melanogenesis in B16 Melanoma Cells and on Tyrosinase Activity in a Cell-Free System B16 cells were cultured in the presence of $100 \mu \mathrm{M}$ MS-818 for $72 \mathrm{~h}$ in order to study the effects of MS-818 on melanogenesis. A preliminary experiment revealed that proliferation of melanoma (B16) cells was scarcely inhibited by MS-818 in the concentration range from 5 to $100 \mu \mathrm{M}$. As shown in Figs. 7A and B, a dark pigment was observed in B16 cells not treated with MS-818, while the accumulation was reduced to about $60 \%$ of the control in the cells treated with MS-818 $(100 \mu \mathrm{M})$, indicating that MS-818 attenuated melanogenesis.

To investigate whether the inhibitory effect of MS-818 on melanogenesis involves direct inhibition of tyrosinase, the inhibitory effect of MS-818 was examined in a cell-free system using mushroom tyrosinase. As shown in Fig. 7C, the tyrosinase activity was hardly inhibited by MS- 818 in the concentration range from 10 to $100 \mu \mathrm{M}$, indicating that the inhibitory effect of MS-818 on melanogenesis is not due to direct inhibition of tyrosinase.

Effect of MS-818 and MS-820 on Protein Expression of MITF and Tyrosinase Since MITF plays a crucial role in melanogenesis as a regulator of tyrosinase, ${ }^{21,22)}$ expression of MITF and tyrosinase was analyzed by Western blotting. As shown in Figs. 8A, B, MS-818 suppressed expression of both MITF and tyrosinase in a dose-dependent manner, while MS820 did not. These data indicate that MS-818 inhibits melanogenesis via suppression of MITF and tyrosinase expression.

Activation of ERK by MS-818 Activation of ERK by MS-818 was examined in B16 melanoma cells, because ERK activation results in MITF phosphorylation, leading to ubiquitination and degradation of MITF. ${ }^{23-25)}$ As shown in Fig. 9, sustained ERK activation was observed from $30 \mathrm{~min}$ after treatment with MS-818 $(100 \mu \mathrm{M})$.
(A)

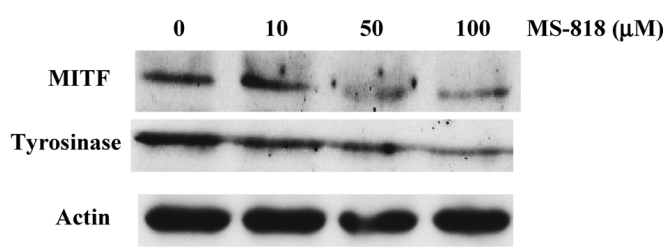

(B)

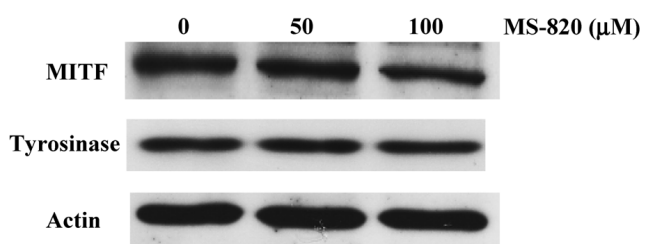

Fig. 8. Effects of MS-818 and MS-820 on Protein Expression of MITF and Tyrosinase

B16 melanoma cells were incubated with MS-818 or MS-820 in the concentration range from 10 to $100 \mu \mathrm{m}$ for $72 \mathrm{~h}$. Whole cell lysates were subjected to Western-blotting analysis using specific antibodies against MITF and tyrosinase. Equal protein loading was confirmed by using anti- $\beta$-actin antibody.

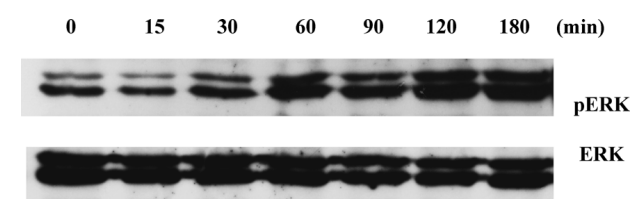

Fig. 9. Time-Dependent Effect of MS-818 on Activation of ERK

B16 melanoma cells were incubated with MS-818 at a dose of $100 \mu \mathrm{M}$ for the times indicated. Whole cell lysates were subjected to Western blotting using specific antibody against phosphorylated ERK. Equal protein loading was confirmed using ERK1/2 antibody.

\section{DISCUSSION}

Environmental UV is injurious, especially to skin, eyes, and the immune system. ${ }^{38)}$ Public health institutions, including the WHO, recommend various ways for humans to protect themselves from the harmful effects of UV radiation, such as the usage of sunscreens, wearing protective clothing, and limiting time in the midday sun. ${ }^{39)}$ However, lifetime UV exposure is expected to increase as the average life expectancy of humans increases. Existing UV protective or skin-whitening agents are not sufficiently effective, ${ }^{40,41)}$ so there is a need for more effective agents.

Heterocyclic pyrimidine compounds have various biological activities, including neurotrophic effects ${ }^{29-33)}$ and angiogenesis. ${ }^{35,36)}$ Here, we investigated the effects of five heterocyclic pyrimidine (MS series) compounds on UVB-induced cell damage and on melanogenesis.

Among the compounds tested in this study, 2-piperadino-6-methyl-5-oxo-5,6-dihydro( $7 H$ )pyrrolo[3,4- $d]$ pyrimidine maleate (MS-818) and 2-piperadino-7-methyl-6-oxo5,6-dihydro(7H)pyrrolo[2,3- $d$ ]pyrimidine maleate (MS-820) showed low cytotoxicity to HaCaT cells. Further, MS-818 significantly and dose-dependently protected the cells from UVB-induced damage, though MS-820, an isomer of MS818 , was ineffective. This result suggested that the structure of MS-818 is critical for the protective function against UVB. One reason for the difference may be that the maximum absorption of MS- 818 lies at around $280 \mathrm{~nm}$, while this is not the case for MS-820 (data not shown). 
TNF- $\alpha$ is known to be elevated in HaCaT cells exposed to $\mathrm{UVB}$, and is associated with apoptotic cell death, inflammation, and immunosuppression. ${ }^{15,16)}$ We found that UVB irradiation $\left(100 \mathrm{~mJ} / \mathrm{cm}^{2}\right)$ significantly elevated TNF- $\alpha$ in $\mathrm{HaCaT}$ cells, and this elevation was suppressed by MS-818 in a dose-dependent manner. Apoptotic cell death was also attenuated by MS- 818 treatment.

Since hyperpigmentation, owing to overproduction and accumulation of melanin in the skin, is considered undesirable, particularly for women, compounds that modulate melanogenesis are of interest. Therefore, the effect of MS-818 on melanogenesis was examined in B16 melanoma cells. Melanogenesis in B16 melanoma cells was potently inhibited by MS-818 at $100 \mu \mathrm{M}$, a concentration that showed little cytotoxicity. Further, MS-818 did not directly inhibit the activity of tyrosinase, the rate-limiting enzyme in melanin synthesis, ${ }^{23)}$ although almost all skin-whitening agents currently used in cosmetics, such as kojic acid, suppress melanogenesis through inhibition of this enzme. ${ }^{42)}$

Since melanin biosynthesis is catalyzed by tyrosinase, the expression of which is strongly regulated by $\mathrm{MITF}^{21,22)}$ the effect of MS-818 on expression of MITF and tyrosinase was examined by Western blotting. It was found that MS-818 dose-dependently suppressed protein expression of MITF and tyrosinase, while MS-820, an isomer of MS-818, did not at any doses. Differences in the activity is considered to be the binding characteristics of each compound with transcriptional factors and other up-stream signaling proteins. These results indicate that MS-818 inhibits melanogenesis through suppression of MITF and tyrosinase expression. It has further been reported that MITF participates in expression of TRP-1 and TRP-2 as well as that of tyrosinase, ${ }^{21,22)}$ and that compounds which can suppress the expression of these factors also have an inhibitory efficacy toward expression of TRP-1 and TRP-2. ${ }^{43,44)}$ Therefore, MS-818 may also be able to influence upon not only the expressions of tyrosinase but TRP-1 and TRP-2. On the other hand, it is reported that expression of TRP-1 and TRP-2 is controlled by a different pathway from that of MITF. ${ }^{4-47)}$ Detailed examination is further required.

The ERK signaling cascade, which plays a crucial role in cell proliferation and differentiation, also participates in down-regulation of MITF. ${ }^{23-25)}$ Inhibition of the ERK pathway by the specific inhibitor PD 98059 causes elevation of tyrosinase activity and melanogenesis, ${ }^{43,48)}$ while activation of ERK results in MITF phosphorylation at serine 73, leading to ubiquitination and degradation of MITF. We found that MS-818 caused sustained activation of ERK in B16 melanoma cells. Overall, our results indicate that the suppression of melanogenesis by MS-818 is due to a decrease of tyrosinase expression mediated by MITF. Activation of ERK also appears to be involved, and the effect of MS-818 on ERK signaling should be further investigated.

In conclusion, MS-818 protected epidermal cells from UVB-induced damage and also suppressed melanogenesis via an MITF-mediated decrease of tyrosinase expression. MS-818 appears to be a promising candidate for a UVBprotective as well as whitening agent for use in cosmetics.

\section{REFERENCES AND NOTES}

1) Nole G., Johnson A. W., Dermatologic Therapy, 17, 57-62 (2004).

2) Gonzalez Maglio D. H., Paz M. L., Ferrari A., Weill F. S., Czerniczyniec A., Leoni J., Bustamante J., Photodermatol. Photoimmunol. Photomed., 21, 311-317 (2005).

3) Sutherland J. C., Griffin K. P., Radiat. Res., 86, 399-409 (1981).

4) Matsumura Y., Ananthaswamy H. N., Toxicol. Appl. Pharmacol., 195, 298-308 (2004).

5) Gloster H. M. Jr., Brodland D. G., Dermatol. Surg., 22, 217-226 (1996).

6) Fisher M. S., Kripke M. L., Science, 216, 1133-1134 (1982).

7) Ullrich S. E., Mutat. Res., 571, 185-205 (2005).

8) Cox N. H., Diffey B. L., Farr P. M., Br. J. Dermatol., 126, 315-319 (1992).

9) Friedmann P. S., Gilchrest B. A., J. Cell. Physiol., 133, 88-94 (1987).

10) Gilchrest B. A., Br. J. Dermatol., 135, 867-875 (1996).

11) Kupper T. S., Chua A. O., Flood P., McGuire J., Gubler U., J. Clin. Invest., 80, 430-436 (1987).

12) Enk C. D., Sredni D., Blauvelt A., Katz S. I., J. Immunol., 154, 48514856 (1995).

13) Köck A., Schwarz T., Kirnbauer R., Urbanski A., Perry P., Ansel J. C., Luger T. A., J. Exp. Med., 172, 1609 -1614 (1990).

14) Curiel-Lewandrowski C., Venna S. S., Eller M. S., Cruikshank W., Dougherty I., Cruz P. D. Jr., Gilchrest B. A., Exp. Dermatol., 12, $145-152$ (2003).

15) Hart P. H., Grimbaldeston M. A., Swift G. J., Sedgwick J. D., Körner H., Finlay-Jones J. J., Eur. J. Immunol., 28, 2893-2901 (1998).

16) Schwarz A., Bhardwaj R., Aragane Y., Mahnke K., Riemann H., Metze D., Luger T. A., Schwarz T., J. Invest. Dermatol., 104, 922927 (1995)

17) Matsunaga T., Hieda K., Nikaido O., Photochem. Photobiol., 54, 403-410 (1991).

18) Kulms D., Schwarz T., Photodermatol. Photoimmunol. Photomed., 16, 195-201 (2000).

19) Libow L. F., Scheide S., DeLeo V. A., Pigment Cell Res., 1, 397-401 (1988).

20) Hearing V. J., Jiménez M., Pigment Cell Res., 2, 75-85 (1989).

21) Fuse N., Yasumoto K., Suzuki H., Takahashi K., Shibahara S., Biochem. Biophys. Res. Commun., 219, $702-707$ (1996).

22) Gaggioli C., Buscà R., Abbe P., Ortonne J. P., Ballotti R., Pigment Cell Res., 16, 374-382 (2003).

23) Marshall C. J., Cell, 80, 179-185 (1995)

24) Sale E. M., Atkinson P. G., Sale G. J., EMBO J., 14, $674-684$ (1995).

25) Bertolotto C., Buscà R., Brunet A., Pagès G., Ortonne J. P., Ballotti R., J. Biol. Chem., 273, 9966 -9970 (1998).

26) Hearing V. J., Tsukamoto K., FASEB J., 5, 2902-2909 (1991).

27) Brenner M., Hearing V. J., Photochem. Photobiol., 84, 539-549 (2008).

28) Briganti S., Camera E., Picardo M., Pigment Cell Res., 16, 101-110 (2003).

29) Awaya A., Kobayashi H., Horikomi K., Tanaka S., Kabir A. M., Yokoyama K., Ohno H., Kato K., Kitahara T., Tomino I., Isayama S., Nakamura S., Biol. Pharm. Bull., 16, 248-253 (1993).

30) Ikeuchi T., Nakatani A., Yamada M., Itokazu N., Awaya A., Hatanaka H., J. Biochem., 123, 423-430 (1998).

31) Koyama Y., Awaya A., Ishikawa N., Fujita S., Tomino I., Yokoyama K., Araki S., Takesue M., Kato K., Ishiguro M., Kitahara T., Kihara N., Baba A., Biol. Pharm. Bull., 20, $138-141$ (1997).

32) Sanjo N., Owada K., Kobayashi T., Mizusawa H., Awaya A., Michikawa M., J. Neurosci. Res., 54, 604-612 (1998).

33) Itoh S., Samejima H., Shinomiya K., Awaya A., Restor. Neurol. Neurosci., 14, 265-273 (1999).

34) Yoshikawa M., Saura R., Mizuno K., Awaya A., Kobe J. Med. Sci., 46, 265-282 (2000).

35) Yasuhara S., Kashiwagi S., Ito H., Awaya A., Int. J. Clin. Pharmacol. Res., 15, 167-174 (1995).

36) Kanemura M., Abe M., Ueda M., Ueki M., Awaya A., Sato Y., Endothelium, 11, 221-230 (2004).

37) Matsumoto K., Haraguchi S., Miyoshi K., Awaya A., Sato E., J. Reprod. Dev., 43, 137-141 (1997).

38) Longstreth J, de Gruijl F. R., Kripke M. L., Abseck S., Arnold F., Slaper H. I., Velders G., Takizawa Y., van der Leun J. C., J. Pho- 
tochem. Photobiol. B, 46, 20-39 (1998).

39) http://www.who.int/uv/intersunprogramme/en/

40) Long T. C., Tajuba J., Sama P., Saleh N., Swartz C., Parker J., Hester S., Lowry G. V., Veronesi B., Environ. Health Perspect., 115, 1631 1637 (2007).

41) Takizawa T., Imai T., Onose J., Ueda M., Tamura T., Mitsumori K., Izumi K., Hirose M., Toxicol. Sci., 81, 43-49 (2004).

42) Solano F., Briganti S., Picardo M., Ghanem G., Pigment Cell Res., 19, $550-571$ (2006).

43) Cowley S., Paterson H., Kemp P., Marshall C. J., Cell, 77, 841-852 (1994).
44) Jang J. Y., Lee J. H., Kang B. W., Chung K. T., Choi Y. H., Choi B. T., Exp. Dermatol., 18, 232-237 (2009).

45) Fang D., Setaluri V., Biochem. Biophys. Res. Commun., 256, 657-663 (1999).

46) Hornyak T. J., Hayes D. J., Ziff E. B., J. Invest. Dermatol., 115, 106 112 (2000).

47) Fang D., Tsuji Y., Setaluri V., Nucleic Acids Res., 30, 3096-3106 (2002).

48) Kim D. S., Hwang E. S., Lee J. E., Kim S. Y., Kwon S. B., Park K. C., J. Cell Sci., 116, 1699-1706 (2003). 